\title{
RESEARCH PAPER \\ PREVALENCE AND ANTIFUNGAL SUSCEPTIBILITY OF CANDIDA SPECIES ISOLATED FROM WOMEN ATTENDING A GYNAECOLOGICAL CLINIC IN KUMASI, GHANA
}

\author{
H. H. Abruquah \\ Microbiology Department and Infectious Disease, KNUST Hospital, \\ KNUST, Kumasi
}

\begin{abstract}
Candidal vulvovaginitis causes extreme discomfort and affects the well being of women. The aim of this study was to determine the prevalence of Candida infections among women attending gynaecological clinic at the Komfo Anokye Teaching Hospital (KATH) in Kumasi and the antifungal susceptibility patterns of the Candida species isolated. A total of 186 high vaginal swabs (HVS) were collected from women suspected of having candidal vulvovaginitis between March and June 2009. Wet mount preparations in potassium hydroxide (KOH) and Gram-stained smears were performed directly on specimens. Cultures for Candida species were done using sabouraud dextrose agar (SDA) (Oxoid, UK) at room temperature $\left(25-28^{\circ} \mathrm{C}\right.$ ). Antifungal susceptibility of the Candida species to amphotericin $B$, fluconazole and itraconazole was assessed using the ATB FUNGUS 3 test kits (bioMerieux, Marcy-l'Etoile, France). Of the $186 \mathrm{HVS}$ cultured, 39 yielded Candida species giving Candida prevalence in HVS during the study period as 21\%. Candida species isolated from HVS specimens were Candida albicans (n=19, 48.7\%), Candida glabrata ( $n=7,17.9 \%)$, Candida tropicalis $(n=4,10.3 \%)$ and Candida dubliniensis ( $n=4$, $10.3 \%)$. Other species isolated were Candida sake $(n=2,5.1 \%)$, Candida krusei $(n=2,5.1 \%)$ and Candida parapsilosis (n=1, 2.6\%). Susceptibility of the isolates to antifungal agents ranged from $66.7 \%$ to $87.2 \%$ with MICs ranging from $\leq 0.125 \mathrm{mg} / \mathrm{l}$ to $8 \mathrm{mg} / \mathrm{l}$. Amphotericin B was the best performing antifungal agents with sensitivity of $87.2 \%$.
\end{abstract}

Keywords: Antifungal susceptibility, Candida species, yeasts infections, Fluconazole, vulvovaginitis

\section{INTRODUCTION}

Yeasts infections of the vagina, commonly known as candidal vulvovaginitis, is a female infection primarily common during the fecund period (Odds, 1988; Sobel, 1992). The prevalence of candidal vulvovaginitis in the world is estimated in the range of 5 to $20 \%$ (Collier et al., 1998). Depending on the age, locality and socio-economic status, the frequency of vaginal Candida isolates has been reported to be between 5 and $48.4 \%$ in women (Abu-Elteen et al., 1997). The prevalence of vulvovaginitis increases in groups such as pregnant or diabetic women, those using oral contraceptives or on long-term antibiotic treatment (Sobel, 1992). Candida albicans is the most common etiologi- 
cal agent of vulvovaginitis but other yeast species such as Candida glabrata, Candida krusei and Candida tropicalis are also encountered (Sobel, 1997). There are no recent published data in the literature to ascertain the true prevalence of candidal vulvovaginitis in Ghana. The aim of this study therefore was to determine the prevalence of vulvovaginal candidiasis among women attending the Komfo Anokye Teaching Hospital in Kumasi and the antifungal susceptibility patterns of the Candida species isolated from these women.

\section{MATERIALS AND METHODS}

The study was conducted at the microbiology laboratory of the Komfo Anokye Teaching Hospital with the approval of the Committee on Human Research, Publications and Ethics (CHRPE) of the School of Medical Sciences of the Kwame Nkrumah University of Science and Technology (KNUST) and the Komfo Anokye Teaching Hospital (KATH). High vaginal swabs routinely delivered at the microbiology laboratory for mycological examination were further used for this research work. Wet mount preparations in $\mathrm{KOH}$ and Gram-stained smears were performed directly on HVS and then observed using the light microscope for yeast cells and hyphae. The samples were cultured on sabouraud dextrose agar (SDA) (Oxoid, UK) and then incubated at room temperature (25$28^{\circ} \mathrm{C}$ ) for 2 to 3 days. Candida yeast cells isolated from the samples were identified to the species level using the germ tube test and the API ID $32 \mathrm{C}$ test kits. The isolates were stored as suspension in $20 \%$ glycerol broth at $-70^{\circ} \mathrm{C}$.

Antifungal susceptibility of the Candida isolates to amphotericin $\mathrm{B}$, fluconazole and itraconazole was assessed using the ATB FUNGUS 3 test kits (bioMerieux, Marcy-l'Etoile, France) according to manufacturer's instruction. The range of concentrations of different antifungal agents tested was at twofold dilutions and included: amphotericin B [AMB (0.5 - 16mg/l)]; fluconazole [FCA (1 - 128mg/l)] and itraconazole [ITR $(0.125-4 \mathrm{mg} / \mathrm{l})]$. The inoculum size was adjusted to turbidity stan- dard equivalent to $2 \mathrm{McF}$ arland. Results were read after 24 to 48 hours of incubation at $37^{\circ} \mathrm{C}$. The yeast, Candida parapsilosis NCTC 3104, was used as quality control strain. Antifungal susceptibility results were analyzed using the interpretive criteria as recommended by Clinical and Laboratory Standard Institute (CLSI) for fluconazole [FCA (S $\leq 8 \mathrm{mg} / \mathrm{l}$; I: 16-32mg/l and $\mathrm{R} \geq 64 \mathrm{mg} / \mathrm{l}$ for Candida species)]; itraconazole [ITR ( $\leq \leq 0.125 \mathrm{mg} / \mathrm{l}$; I: $0.25-0.5 \mathrm{mg} / \mathrm{l}$ and $\mathrm{R} \geq 1 \mathrm{mg} / \mathrm{l}$ for Candida species)]. For amphotericin B, CLSI interpretive criteria for Candida are not available. However, it has been suggested that Candida isolates for which amphotericin B MICs were $\leq 1 \mathrm{mg} / \mathrm{l}$ were considered susceptible and so it was used as cut off value to separate susceptible isolates from the resistant ones (CLSI, 2002).

\section{RESULTS}

Of the 186 high vaginal swabs cultured, 39 yielded Candida species (21\%). Candida species isolated from high vaginal swabs were Candida albicans $(\mathrm{n}=19,48.7 \%)$, Candida glabrata $(\mathrm{n}=7,17.9 \%)$, Candida tropicalis $(\mathrm{n}=4,10.3 \%)$ and Candida dubliniensis $(\mathrm{n}=4$, $10.3 \%)$. Other species isolated were Candida sake $(\mathrm{n}=2,5.1 \%)$, Candida krusei $(\mathrm{n}=2,5.1 \%)$ and Candida parapsilosis $(\mathrm{n}=1,2.6 \%)$. The distribution of different species of Candida among the different age groups is shown in Table 1 . The results obtained also showed that the 15-20 year group had the highest frequency of Candida positive samples followed by the 26 -30 year age group. The age groups $46-50$ years and the above 51 year bracket had the lowest frequency of Candida (2.6\%). Statistical analysis of the data using one sample t- test (SPSS version 17) indicates that there was significant difference in the prevalence among the different age- groups $(p-$ value $=0.004)$.

The results of the antifungal susceptibility of the 39 Candida yeast isolates against amphotericin B fluconazole and itraconazole as determined by the ATB FUNGUS 3 test method are shown in Table 2 below. 
Table 1: Distribution of different Candida species within different age groups

\begin{tabular}{|c|c|c|c|c|c|c|c|c|}
\hline \multirow[b]{2}{*}{$\begin{array}{l}\text { Age } \\
\text { group }\end{array}$} & \multicolumn{8}{|c|}{ Yeast species } \\
\hline & $\begin{array}{c}\text { C. } \\
\text { albicans }\end{array}$ & $\begin{array}{c}\text { C. } \\
\text { glabrata }\end{array}$ & $\begin{array}{c}\text { C. } \\
\text { tropicalis }\end{array}$ & $\begin{array}{c}C . \\
\text { dubliniensis }\end{array}$ & $\begin{array}{c}\text { C. } \\
\text { krusei }\end{array}$ & $\begin{array}{c}\text { C. } \\
\text { sake }\end{array}$ & $\begin{array}{c}\text { C. } \\
\text { parapsilosis }\end{array}$ & $\begin{array}{c}\text { Total } \\
(\%)\end{array}$ \\
\hline $15-20$ & 5.0 & 3.0 & 1.0 & - & 1.0 & - & - & $10(25.6)$ \\
\hline $21-25$ & 4.0 & - & - & - & - & - & - & $4(10.3)$ \\
\hline $26-30$ & 2.0 & 3.0 & 1.0 & 2.0 & - & 1.0 & - & $9(23.0)$ \\
\hline $31-35$ & - & 1.0 & 1.0 & 1.0 & - & 1.0 & 1.0 & $5(12.8)$ \\
\hline $36-40$ & 2.0 & - & 1.0 & 1.0 & 1.0 & - & - & $5(12.8)$ \\
\hline $41-45$ & 4.0 & - & - & - & - & - & - & $4(10.3)$ \\
\hline $46-50$ & 1.0 & - & - & - & - & - & - & $1(2.6)$ \\
\hline$\geq 51$ & 1.0 & - & - & - & - & - & - & $1(2.6)$ \\
\hline $\begin{array}{c}\text { Total } \\
(\%)\end{array}$ & $19(48.7)$ & 7(17.9) & $4(10.3)$ & $4(10.3)$ & $2(5.1)$ & $2(5.1)$ & $1(2.6)$ & $\begin{array}{c}39 \\
(100.0)\end{array}$ \\
\hline
\end{tabular}

\section{DISCUSSION}

Candida infection of the vagina is a common problem that causes significant morbidity and affects the well being of women (Asticcioli et al., 2009). The results showed in the studied population Candida prevalence of $21 \%$ from high vaginal swabs. This is lower than the $40.6 \%$ and $51.5 \%$ reported by Enweani et al. (2001) among non-contraceptive and contraceptive users in Nigeria. The high prevalence recorded among the contraceptive users in Enweani's study could be attributed to the presence of oestrogen and progesterone hormones in the contraceptive that increased glycogen level in the vaginal fluid and hence promoted the overgrowth of Candida species (Rippon, 1988; Njoku-Obi et al., 1976). However, the $21 \%$ prevalence reported in this study is consistent with findings from studies of the general female population (Gross et al., 2007; Mohanty et al., 2007; Falleiros de Padua et al., 2003).

This study also showed that the 15-20 year age group had the highest frequency $(n=10,25.6 \%)$ of Candida isolation from high vaginal swabs followed by the 26-30 year age group $(n=9$, $23.0 \%$ ). Statistical analysis of the data using one- sample t- test (SPSS version 17) indicates that there was significant difference $(\mathrm{p}$-value $=$ 0.033 ) in prevalence between the $15-20$ and 26- 30 year age groups. This finding contradicts that of Okungbowa et al. (2003) who reported in Nigeria that the 26-30 year age group followed by the 21-25 year group had the highest frequency of Candida positive samples in their study. Also Ako-Nai et al. (1993) reported in Nigeria that the age group 20-25years was the group in which genital candidiasis occurs most frequently. They suggested in their study that there could be a link between the disease and sexual activity.

The high prevalence of Candida isolation within the 21-30 age groups supports the reports of Enweani et al. (1987) which showed that $40.7 \%$ of total samples of asymptomatic female students of University of Jos, Nigeria had vaginal candidiasis. They reported that the 20-30 year age could be a vulnerable group of candidal vulvovaginitis probably due to use of contraceptives and increased sexual activity.

The most frequent Candida species isolated from high vaginal swab in this study was Candida albicans, followed by Candida glabrata. This finding compares favourably with that of 


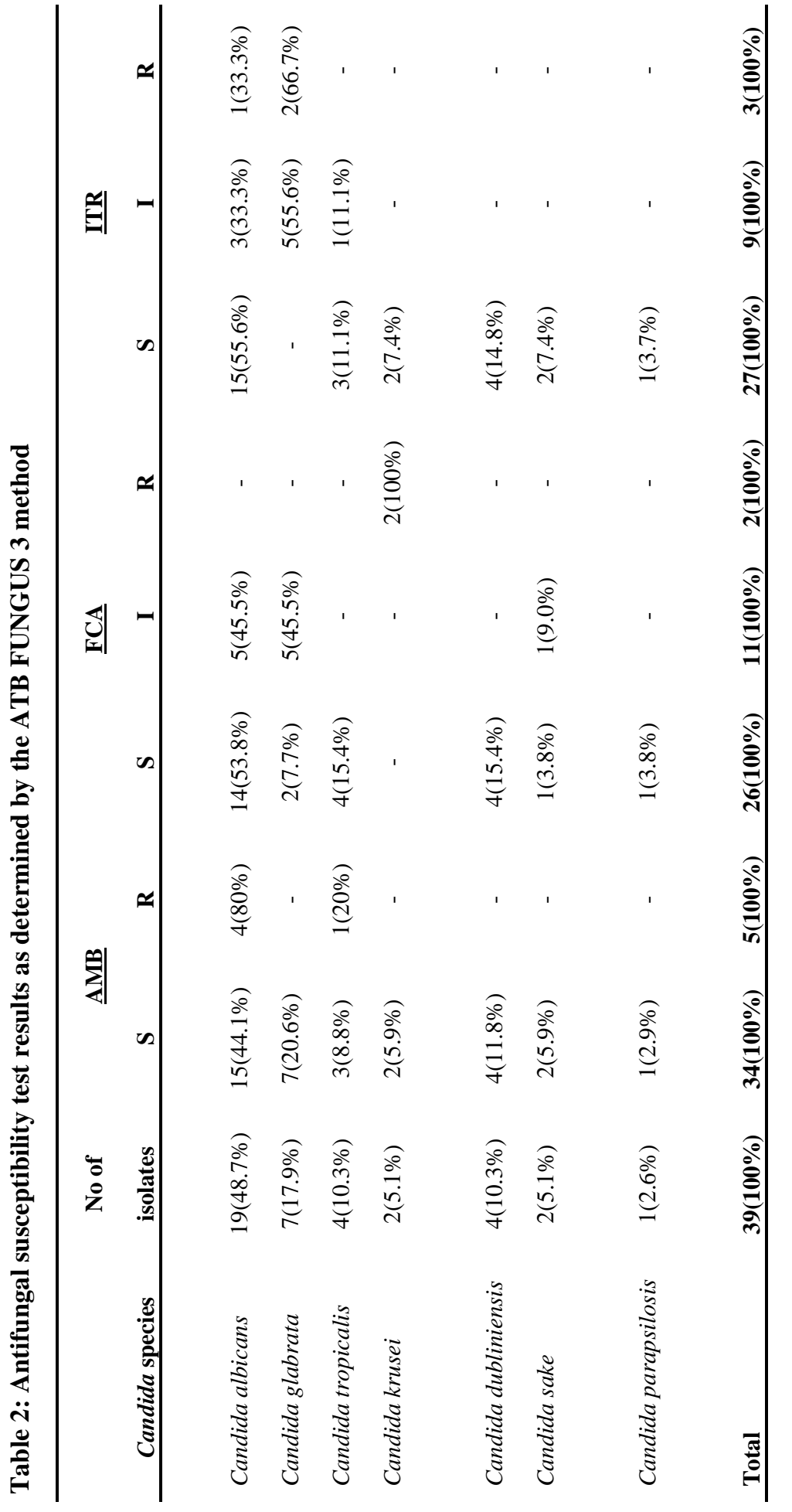

Journal of Science and Technology @ KNUST August 2012 
other studies in other parts of the world (Ellabib and ElJariny, 2001; Asticcioli et al., 2009). However, in the study of Okungbowa et al. (2003) in Nigeria, it was reported that Candida glabrata was the commonest yeast isolated from both urinary and high vaginal specimens followed by Candida albicans and Candida tropicalis, a study in which urinary and high vaginal swabs isolates were combined.

Fluconazole is one of the first-line antifungal drugs that are used in the treatment of infections due to Candida species other than Candida krusei and some Candida glabrata isolates (Patel, 2000; Wolff et al., 2000). In this study, it was found that none of the 19 Candida albicans isolated from high vaginal swabs was resistant to fluconazole even though $26.3 \%(5 / 19)$ were in the intermediate category. This finding is consistent with findings of Sobel et al. (2004) who reported no fluconazole resistance among the 401 Candida albicans recovered from women with candidal vaginitis in USA. Also Ribeiro et al. (2000) reported in Brazil that all the 56 Candida albicans tested against fluconazole were susceptible. However, another study in USA reported fluconazole resistance to be $3.6 \%$ among Candida albicans isolates collected from candidal vaginitis patients (Sobel et al., 2003). The finding of $26.3 \%$ (5/19) of Candida albicans isolates in the intermediate category of the sensitivity testing could be considered alarming because it is an indication of the potential for development of fluconazole resistance.

Findings from the study showed $71.4 \%$ of Candida glabrata isolates were found to be in the intermediate category for fluconazole which confirms those reported in earlier studies that Candida glabrata isolates often generate a high fluconazole MICs (Pfaller, 1999; Arzeni et al., 1997; Richter et al., 2005). Resistance of isolates to itraconazole and amphotericin $\mathrm{B}$ ranged from 7.7 to $12.8 \%$ respectively. This compares with the result of Araj et al. (1998).

\section{CONCLUSION}

The prevalence of vulvovaginal candidiasis among women attending gynaecological clinic at the Komfo Anokye Teaching Hospital in Kumasi was $21 \%$. Candida albicans was the most frequent yeast isolated from high vaginal swabs followed by Candida glabrata. Amphotericin B was found to be the best performing antifungal agents against the vaginal Candida isolates with susceptibility rate of $87.2 \%$.

\section{ACKNOWLEDGEMENT}

We are very grateful to the management and the staff of the microbiology laboratory of the Komfo Anokye Teaching Hospital in Kumasi for granting us the permission to collect vaginal samples from patients and for valuable help at the laboratory. We also wish to extend our sincere thanks to Dr Mills- Robertson of the Center for Scientific Research into Plants Medicine for helping us secure the ID $32 \mathrm{C}$ test kits and Dr Frank Huenger, former Head of laboratories, Kumasi Center for Collaborative Research (KCCR), Kumasi for providing the apiweb identification software used in identification of the Candida species.

\section{REFERENCES}

Abu-Elteen, K. H., Abdul-Malek, A. M. and Abdul-Wahid, N. A. (1997). "Prevalence and susceptibility of vaginal yeast isolates in Jordan." Mycoses, 40 (5-6): 179-185.

Ako-Nai, A. K., Kassim, O. O., Adeniram, M. O. and Taiwo, O. (1993). "A study of urinary tract infections at lle Ife, Nigeria. East African Med. J., 15 (3):10-14.

Asticcioli, S., Sacco, L., Daturi, R., Matti, C., Nucleo, E., Zara, F. and Pagani, L. (2009). "Trends in frequency and in vitro antifungal susceptibility patterns of Candida isolates from women attending the STD outpatients clinic of a tertiary care hospital in Northern Italy during the years 2002-2007." New. Microbiol., 32(2): 199-204.

Araj, G. F., Daher, N. K. and Tabborah, Z. A. 
44

(1998). “Antifungal susceptibility of Candida isolates at the American University of Beirut Medical Center". Int. J. Antimicrob. Agents, 10: 291-6.

Arzeni, D., Del-Poeta, M., Simonetti, O., Offidani, A. M., Lamura, L., Balducci, M., Cester, N., Giacometti, A. and Scalise, G. (1997). "Prevalence and antifungal susceptibility of vaginal yeasts in outpatients attending a gynecological center in Ancona, Italy." Eur. J. Epidemiol., 13(4): 447-50.

Clinical and Laboratory Standard Institute (CLSI), (2002). Reference method for broth dilution antifungal susceptibility testing of yeasts, M27- A2.

Collier, L., Balows, A. and Sussman, M. (1998). “Topley \& Wilson's Microbiology and microbial infections." $9^{\text {th }} \mathrm{Ed}$, vol 4; Arnold, London, Sydney, Auckland, New Yorke.

Ellabib, M. S. and ElJariny, I. A. (2001). "In vitro activity of 6 antifungal agents on Candida species isolated as causative agents from vaginal and other clinical specimens." Saudi. Med. J., 22 (10): 860-863.

Enweani, I. B., Gugnani, H. C., Okobia, R. and Ojo, S. B. (2001). "Effect of contraceptives on the prevalence of vaginal colonization with Candida species in Edo State, Nigeria." Rev. Iberoam. Micol., 18(4): 171- 173.

Enweani, I. B., Ogbonna, C. I., and Kozak, W. (1987). "The incidence of candidiasis amongst the asymptomatic female students of the University of Jos, Nigeria." Мycopathologia, 99: 135-141

Falleiros de Padua, F., Guilhermetti, E. and Svidzinski, T. I. E. (2003). "In vitro activity of antifungal agents on yeasts isolated from vaginal secretion." Acta. Scientiarum. Health Sciences Maringa, 25(1): 51-54.
Gross, N. T, Arias, M. L., Moraga, M., Baddasarow, Y. and Jarstrand, C. (2007). "Species distribution and susceptibility to azoles of vaginal yeasts isolated from prostitutes." Infect. Dis. Obstet. Gynecol., 2007: 82412.

Mohanty, S., Xess, I., Hasan, F., Kapil, A., Mittal, S. and Tolosa, J. E. (2007). "Prevalence and susceptibility to fluconazole of Candida species causing vulvovaginitis." Indian. J. Med. Res., 126: 216 -219.

Njoku-Obi, A. N. U., Okafor, J. I., Gugnani, H. C. (1976). "Yeast-like fungi recovered from normal human skin in Nsuka, Nigeria." Ant. Van Leeuw., 42: 101-105.

Odds, F. C. (1988). Candida and candidosis: A review and bibliography. $2^{\text {nd }}$. Ed., London: Balliere Tindall: 68-92Okungbowa, F. I., Isikhuemhen, O.S. and Dede, A.P.O. (2003) "The distribution frequency of Candida species in the genitourinary tract among symptomatic individuals in Nigerian cities." Rev. Iberoam. Micol., 20(2): 60-63.

Patel, R. (2000). "Prophylactic fluconazole in liver transplant recipients: A randomized, double-blind, placebo-controlled trial" (Reprinted from Ann. Intern. Med. 131, 729-737). Liver transplant, 6: 376-379.

Pfaller, M. A., Messer, S. A., Hollis, R. J., Jones, R. N., Doerm, G. V., Brandt, M. E. and Hajjeh, R. A. (1999). "Trends in species distribution and susceptibility to fluconazole among blood stream isolates of Candida species in the United States." Diagn. Microbiol. Infect. Dis., 33(4): 217-222.

Ribeiro, M. A., Dietze, R., Paula, C. R., DaMatta, D. A. and Colombo, A. L. (2000). "Susceptibility profile of vaginal yeast isolates from Brazil." Mycopathologia, 15: 5 10

Richter, S. S., Galask, R. P., Messer, S. A., 
Hollis , R. J., Diekema, D. J. and Pfaller, M. A. (2005). Antifungal susceptibilities of Canndida species causing vulvovaginitis and epidemiology of recurrent cases. J. Clin. Microbiol., 43: 2155- 2162.

Rippon, J. W. (1988). "Candidosis and the pathogenic yeast. In Medical Mycology- The pathogenic fungi and the pathogenic actinomycetes." Philadelphia,W. B. Saunders: 536581.

Sobel, J. D. (1992). "Pathogenesis and treatment of recurrent vulvovaginal candidiasis." Clin. Infect. Dis., 14 Suppl (1:S1): 48 - 53.

Sobel, J. D., Wiesenfeld, H. C., Martens, M., Danna, P., Hooton, T. M. and Rompalo, A. (2004). "Maintenance fluocnazole therapy for recurrent vulvovaginal candidiasis." N. Engl.
J. Med., 351: 876 - 883.

Sobel, J. D., Zervos, M., Reed, B. D., Hooton, T. M., Soper, D. and Nyirjesy, P. (2003). "Fluconazole susceptibility of vaginal isolates obtained from women with complicated Candida vaginitis: clinical implications." Antimicrob. Agents. Chemother., 47: 34 - 8.

Wolff, S. N., Fay, J., Stevens, D., Herzig, R. H., Pohlman, B., Bolwell, B., Lynch, J., Ericson, S., Freyetes, C. O., LeMaistre, F., Collins, R., Pineiro, L., Greer, J., Stein, R., Goodmand, S.A., Dummer, S. (2000). "Fluconazole vs low-dose amphotericin B for the prevention of fungal infections in patients undergoing bone marrow transplantation: A study of the North American Marrow Transplant group." Bone, Marrow Transplant Group. Bone MT 859. 25: 853-859. 